\title{
Diabetic Complications among Adult Diabetic Patients of a Tertiary Hospital in Northeast Ethiopia
}

\author{
Asrat Agalu Abejew, ${ }^{1}$ Abebe Zeleke Belay, ${ }^{1}$ and Mirkuzie Woldie Kerie ${ }^{2}$ \\ ${ }^{1}$ Department of Pharmacy, College of Medicine and Health Sciences, Wollo University, P.O. Box 1145, Dessie, Ethiopia \\ ${ }^{2}$ Department of Health Services Management, College of Public Health and Medical Sciences, Jimma University, \\ P.O. Box 1637, Jimma, Ethiopia
}

Correspondence should be addressed to Asrat Agalu Abejew; asratagl@yahoo.com

Received 17 September 2014; Revised 18 January 2015; Accepted 18 January 2015

Academic Editor: Guang-Hui Dong

\begin{abstract}
Copyright (C) 2015 Asrat Agalu Abejew et al. This is an open access article distributed under the Creative Commons Attribution License, which permits unrestricted use, distribution, and reproduction in any medium, provided the original work is properly cited.
\end{abstract}

\begin{abstract}
Background. The diabetic complications are becoming common community problems. The outcomes of diabetic complications are increased hospitalization, increased direct patient costs, and mortality. In Dessie, the prevalence of the diabetic complications is not well studied so far. Thus, the aim of this study is to assess prevalence of diabetic complications and associated factors among adult diabetic patients of Dessie Referral Hospital, Northeast Ethiopia. Methods. Cross-sectional study was conducted in the diabetic clinic of Dessie Referral Hospital from April to May 31, 2013. All diabetic patients who visited the clinic during the study period were included. Data was collected using interview guided self-administered questionnaire. Presence of complications and the type of medications the patient was on were identified through review of patient records. Data were cleaned, coded, and entered into SPSS for Windows version 17.0. Descriptive statistics and chi-square tests were carried out to meet the stated objective. The Results. Overall 129 (59.7\%) of the patients were found to have been affected by one or more of the diabetic complications. Complications were identified mainly among type II diabetic patients. The age of patients $(P$ value- 0.048$)$, type of diabetes $(P$ value- 0.00$)$, and medication $(P$ value-0.00) were strongly associated with the occurrence of diabetic complication but self-reported adherence, attitude, and knowledge level of patients and the family history were not associated with the presence of complication. Conclusion. The prevalence of complications among diabetic patients in Dessie Referral Hospital was high. Targeted counseling and health information provision to the patients by the clinical staff will be helpful in reducing avoidable morbidity and mortality in the patients.
\end{abstract}

\section{Introduction}

Diabetes mellitus (DM) is a group of common metabolic disorders that share the phenotype of hyperglycemia, which are caused by a complex interaction of genetics and environmental factors. It is the leading cause of end-stage renal disease (ESRD), traumatic lower extremity amputations, and adult blindness. It also predisposes to cardiovascular diseases. With an increasing incidence worldwide, DM will be a leading cause of morbidity and mortality in the foreseeable future. The goal of treatment for DM is to prevent mortality and complications by normalizing blood glucose level. But blood glucose level might be increased despite appropriate therapy resulting in complications, such as disturbances in fat metabolism, nerve damage, and eye disease [1-5].

Different studies, in fact, of different methodological quality [6] have documented the complications of diabetes in different setups including hospitals and the community [79] including its contributing factors like poor attitude [10-13] and adherence [14-17]. These all affect the treatment outcome and may lead to complications and thus to death $[18,19]$.

Studies have reported that diabetes and its complications are among the common reasons for inpatient admissions, accounting for about $4.4 \%$ [18] of total admissions leading to about $3.4 \%[20]$ to $32.5 \%$ [19] total deaths. The prevalence of chronic complications varies from $52.0 \%$ to $74.2 \%$ [7, 
TABLE 1: Characteristics of the diabetic patients in Dessie Referral Hospital, 2013.

\begin{tabular}{|c|c|}
\hline Variable & Frequency (\%) \\
\hline \multicolumn{2}{|l|}{ Sex } \\
\hline Male & $125(57.9)$ \\
\hline Female & $91(42.1)$ \\
\hline Total & $216(100)$ \\
\hline \multicolumn{2}{|l|}{ Age } \\
\hline$\leq 30$ & $53(24.5)$ \\
\hline $31-45$ & $51(29.6)$ \\
\hline$\geq 45$ & $112(51.9)$ \\
\hline Total & $216(100)$ \\
\hline \multicolumn{2}{|l|}{ Religion } \\
\hline Muslim & $157(72.7)$ \\
\hline Orthodox & $58(26.9)$ \\
\hline Protestant & $1(0.5)$ \\
\hline Total & $126(100)$ \\
\hline \multicolumn{2}{|l|}{ Ethnicity } \\
\hline Amhara & $204(94.4)$ \\
\hline Oromo & $6(2.8)$ \\
\hline Tigrie & $3(1.4)$ \\
\hline Others & $3(1.4)$ \\
\hline Total & $216(100)$ \\
\hline \multicolumn{2}{|l|}{ Educational status } \\
\hline Illiterate & $99(45.8)$ \\
\hline $1-8$ & $63(29.2)$ \\
\hline $9-12$ & $31(14.4)$ \\
\hline Higher education & $23(10.6)$ \\
\hline Total & $160(100)$ \\
\hline \multicolumn{2}{|l|}{ Marital status } \\
\hline Never married & $94(43.5)$ \\
\hline Married & $93(43.1)$ \\
\hline Divorced & $11(5.1)$ \\
\hline Widowed & $18(8.3)$ \\
\hline Total & $216(100)$ \\
\hline \multicolumn{2}{|l|}{ Current Job } \\
\hline Gov’t employee & $17(11.8)$ \\
\hline Merchant & $11(7.6)$ \\
\hline Farmer & $43(29.9)$ \\
\hline Retired & $12(8.3)$ \\
\hline Housewife & $23(16.0)$ \\
\hline Others ${ }^{* *}$ & $38(26.4)$ \\
\hline Total & $144(100)$ \\
\hline \multicolumn{2}{|c|}{ Duration since diagnosed } \\
\hline$<5$ & $93(43.1)$ \\
\hline $5-9$ & $79(36.6)$ \\
\hline $10-14$ & $24(11.1)$ \\
\hline $15-19$ & $8(3.7)$ \\
\hline$\geq 20$ & $12(5.6)$ \\
\hline Total & $216(100)$ \\
\hline \multicolumn{2}{|l|}{ Monthly income } \\
\hline$<100$ birr & $185(85.6)$ \\
\hline 100-199 birr & $6(2.8)$ \\
\hline 200-299 birr & $4(1.9)$ \\
\hline
\end{tabular}

TABLE 1: Continued.

\begin{tabular}{lc}
\hline Variable & Frequency (\%) \\
\hline $300-499$ birr & $12(5.6)$ \\
$>500$ birr & $9(4.2)$ \\
Total & $\mathbf{2 1 6 ( 1 0 0 )}$ \\
\hline
\end{tabular}

Others: ${ }^{* *}$ student, mechanic, daily laborer.

TABLE 2: The regimen and specific drugs used to manage types I and II diabetes in Dessie Referral Hospital, $2013(n=216)$.

\begin{tabular}{lc}
\hline & Frequency (\%) \\
\hline Regimen & \\
Oral hypoglycemic agents & $111(51.4)$ \\
Insulin only & $102(47.2)$ \\
Oral hypoglycemic agents and insulin & $3(1.4)$ \\
Specific drugs & \\
$\mathrm{NPH}^{* *}$ insulin & $102(47.2)$ \\
Glibenclamide and metformin & $62(28.7)$ \\
Metformin & $31(14.4)$ \\
Glibenclamide & $18(8.3)$ \\
Metformin and NPH insulin & $3(1.4)$ \\
Total & $\mathbf{2 1 6 ( 1 0 0 )}$ \\
\hline
\end{tabular}

$\mathrm{NPH}^{* *}$ neutral protamine Hagedorn.

$8,21,22]$. The most common chronic complications were erectile dysfunction (64\%) [23], visual disturbance $(33.8 \%)$ [7], and cardiovascular disorders (30.1\%) [22], though hypertension alone was (68\%) [24], neuropathy (29.5\%) [7], and nephropathy (15.7\%) [7]. Likewise acute complications had similar trend which ranges $30.5 \%$ among which diabetic ketoacidosis (DKA) was 71\%, followed by hypoglycemia (19.4\%) but hyperosmolar hyperglycemic state (HHS) was insignificant [7]. The common risk factors for occurrence of complications were gender [10], long duration with diabetes [21], poor and inadequate glycemic control [9], negative attitude towards diabetes $[9,11,25,26]$, poor treatment adherence $[14,27,28]$, and poor knowledge about the disease and its management $[9,11]$. Thus, better understanding of perceptions and attitudes among both patients and providers is needed to guide initiatives to improve the management of diabetes $[6,16]$.

Hence, the common causes of diabetic complications are poor control of diabetes either due to nonadherence, poor attitude towards the disease and its complications, unhealthy diet, and insufficient physical activity, and due to poor management by the health care professionals $[10,18,29,30]$. On top of these complications diabetes can predispose the patient for different infections [7, 19, 21, 31, 32]. The final outcome of diabetes is a disability, and/or death [19, 21, 29, 32], and of course has great economic impact which is direct (medical and treatment costs) and indirect (costs of hospitalizations, loss of vision, lower extremity amputations, kidney failure, and cardiovascular events) $[33,34]$. Thus, prevention is most cost effective than treatment and management of diabetic complications $[35,36]$.

Most of the studies cited above are from the developed countries $[30,35,37]$; to our knowledge such studies are 
Table 3: Distribution of variables based on the type of diabetes in Dessie Referral Hospital, 2013 ( $n=216)$.

\begin{tabular}{|c|c|c|c|c|}
\hline \multirow{2}{*}{ S. no. } & \multirow{2}{*}{ Variables } & \multicolumn{2}{|c|}{ Type of diabetes } & \multirow{2}{*}{ Total } \\
\hline & & Type I (\%) & Type II (\%) & \\
\hline \multirow{4}{*}{1} & Is there complication & & & \\
\hline & Yes & $24(35.8)$ & $105(70.5)$ & $129(59.7)$ \\
\hline & No & $43(64.2)$ & $44(29.5)$ & $87(40.3)$ \\
\hline & Total & $67(100)$ & $149(100)$ & $216(100)$ \\
\hline \multirow{4}{*}{2} & Sex of patients & & & \\
\hline & Male & $41(61.2)$ & $84(56.4)$ & $125(57.9)$ \\
\hline & Female & $26(48.8)$ & $65(43.6)$ & $91(42.1)$ \\
\hline & Total & $67(100 \%)$ & $149(100)$ & $216(100)$ \\
\hline \multirow{5}{*}{3} & Age category & & & \\
\hline & $<30$ & $31(46.3)$ & $22(14.8)$ & $53(24.5)$ \\
\hline & $31-45$ & $24(35.8)$ & $27(18.1)$ & $51(23.6)$ \\
\hline & $>45$ & $12(17.9)$ & $100(67.1)$ & $112(51.9)$ \\
\hline & Total & $67(100)$ & $149(100)$ & $216(100)$ \\
\hline \multirow{5}{*}{4} & Family history of pat & & & \\
\hline & Present & $17(25.4)$ & $16(10.7)$ & $33(15.3)$ \\
\hline & No family history & $47(70.1)$ & $124(83.2)$ & $171(79.2)$ \\
\hline & I don't know & $3(4.5)$ & $9(6.0)$ & $12(5.6)$ \\
\hline & Total & $67(100)$ & $149(100)$ & $216(100)$ \\
\hline \multirow{7}{*}{5} & Category of duration & & & \\
\hline & $<5$ & $21(31.3)$ & $72(48.32)$ & $93(43.1)$ \\
\hline & $5-9$ & $37(55.2)$ & $42(28.2)$ & $79(36.6)$ \\
\hline & $10-14$ & $7(10.4)$ & $17(11.4)$ & $24(11.1)$ \\
\hline & $15-19$ & 0 & $8(5.4)$ & $8(3.7)$ \\
\hline & $>20$ & $2(3)$ & $10(6.7)$ & $12(5.6)$ \\
\hline & Total & $67(100)$ & $149(100)$ & $216(100)$ \\
\hline \multirow{4}{*}{6} & Overall knowledge sc & & & \\
\hline & Good & $37(55.2)$ & $71(47.7)$ & $108(50)$ \\
\hline & Negative/poor & $30(44.8)$ & $78(52.3)$ & $108(50)$ \\
\hline & Total & $67(100)$ & $149(100)$ & $216(100)$ \\
\hline \multirow{4}{*}{7} & Self-reported adhere & & & \\
\hline & Good & $19(28.4)$ & $47(31.5)$ & $66(30.6)$ \\
\hline & Poor & $48(71.6)$ & $102(68.5)$ & $150(69.4)$ \\
\hline & Total & $67(100)$ & $149(100)$ & $216(100)$ \\
\hline \multirow{4}{*}{9} & Overall attitude scor & & & \\
\hline & Good & $37(55.2)$ & $75(50.3)$ & $112(51.9)$ \\
\hline & Negative/bad & $30(44.8)$ & $74(49.7)$ & $104(48.1)$ \\
\hline & Total & $67(100)$ & $149(100)$ & $216(100)$ \\
\hline
\end{tabular}

lacking in Ethiopia and other similar settings. Thus, this study is aimed at determining the prevalence of diabetes related complications and associated risk factors among diabetic patients of a referral hospital in Northeastern Ethiopia.

\section{Methods and Materials}

2.1. Study Setting. A cross sectional study was conducted from April to May 31, 2013, in the diabetic clinic of Dessie Referral Hospital, located in Dessie town, northeast Ethiopia, $400 \mathrm{~km}$ from Addis Ababa. This hospital is the only referral hospital in the Northeastern part of Ethiopia. There are 165 health professionals working in the hospital. In the hospital there are different clinics among which the diabetic followup clinic is the one serving for treatment and followup of diabetic patients coming to the hospital. The service is provided in the clinic twice a week on every Tuesday and Thursday.

2.2. Study Participants. All diabetic patients visited the adult diabetic clinic of the hospital during the study period. Since all diabetic patients were included in the study, sample size determination and sampling techniques were not used.

2.3. Data Collection Process. Pretested data was collected by four nurses trained for the purpose of the data collection. All 
TABle 4: Distribution of chronic diabetic complications in Dessie Referral Hospital, April-June, 2013.

\begin{tabular}{lcc}
\hline S. no. & Complications & Frequency (\%) \\
\hline 1 & Hypertension & $39(43.3)$ \\
2 & Visual disturbance & $26(28.9)$ \\
3 & Neuropathy & $13(14.4)$ \\
4 & Foot ulceration & $4(4.4)$ \\
5 & Foot ulceration & $4(4.4)$ \\
6 & Nephropathy & $2(2.2)$ \\
7 & Impotence & $2(2.2)$ \\
8 & Total & $\mathbf{9 0 ( 1 0 0 )}$ \\
\hline
\end{tabular}

patients visiting the hospital during the three-month period of data collection period were given the self-administered questionnaires and get interviewed if they do not read and write. Patients who visited the hospital for the second time were excluded from study and the first visit's data was taken. The questionnaire contains 18 knowledge, 19 attitude, and 16 practice related questions in addition to 16 general and sociodemographic questions. In addition the last one-month adherence was assessed based on the patients report. Diagnosis of diabetic complications was done by physician and complications and laboratory results were taken from patient cards. The collected data were cleared and checked every day for completeness and consistency before processing.

2.4. Data Processing and Analysis. Collected data were edited, coded, and entered into SPSS for Windows version 17. Descriptive statistics was computed to determine frequency, means, and standard deviations whereas chi-square tests were carried out to determine the association between variables.

2.5. Ethical Consideration. Prior to the study ethical approval was obtained from the ethical review board of Wollo University. The management of the Hospital was requested for cooperation with a formal letter from Wollo University (WU). During and after the data collection process all hospitals and patient-related data were kept confidential. Each study participant signed written consent to participate in the study.

\subsection{Operational Definition and Terms}

(i) Good self-reported adherence: patients who answered correctly more than or equal to mean score.

(ii) Poor self-reported adherence: patients who answered below the mean score.

(iii) Good attitude: patients who answered correctly more than mean score.

(iv) Poor/negative attitude: patients who answered below the mean score.

(v) Good knowledge: patients who answered correctly more than mean score.

(vi) Poor knowledge: patients who answered below the mean score. (vii) Acute complications: including diabetic ketoacidosis and hyperosmolar hyperglycemic.

(viii) Chronic complications: including vascular (microvascular and macrovascular) and nonvascular complications of diabetes.

\section{Results}

3.1. Sociodemographic Characteristics of Diabetic Patients. Two hundred and sixteen (216) diabetic patients who came to the followup clinic during the 2-month period of data collection were included in the study. The majority of the patients (57.4\%) were males, Amhara by ethnic group (94.4\%) and Muslims by religion (72.7\%). The median age of the patients was $45( \pm 17.677)$ and they were known diabetic patients for the mean duration of $5.00( \pm 5.70)$ years (Table 1$)$.

The majority of the patients, $145(67.1 \%)$, were of type II with the remaining $71(32.9 \%)$ being type I patients. The medications used for the treatment of diabetes were oral hypoglycemic agents, 111 (51.39\%), either in combination or alone. But it was noted that insulin was used for both type I and II diabetics to manage the complications (Table 2).

3.2. Prevalence of Diabetic Complications among Diabetic Patients. The overall complications were 129 (59.7\%) of which 105 (48.6\%) were from type II patients. When we see the type specific complications, 105 (70.5\%) and 24 (35.8\%) were among types II and I diabetes, respectively. Attitude 37 (55.2\%) and knowledge levels 37 (55.2\%) are better among the type I diabetic patients when compared to type II patients (Table 3).

More than half, 129 (59.7\%), of the patients have experienced at least one complication. About 90 (58.8\%) and $63(41.2 \%)$ of patients have experienced chronic and acute complications, respectively. Hypertension 39 (43.3\%), visual disturbance 26 (28.9\%), and neuropathy 13 (14.4\%) were the three most common chronic complications in the diabetic clinic (Table 4), whereas the three most common acute diabetic complications were DKA 43 (68.3\%), hypoglycemia 15 (28.3.7\%), and HHS 5 (7.9\%).

3.3. Factors Associated with Diabetic Complications. The age of patients, type of diabetes, the regimen, and specific medications the patient is taking were strongly associated with the presence of complication but it has to be noted that selfreported adherence, attitude and knowledge level of patients, as well as the average blood glucose level, and the family history, were not associated with the presence of complication (Table 5). Close to nine in ten, 183 (86.11\%), the three-month average blood glucose level is still elevated.

\section{Discussion}

This study examines diabetic complications in the diabetic clinic in referral hospital. It is highlighted that diabetic complications are common in the Ward in which the majority were among type II patients and around $41 \%$ of patients have 
TABLE 5: Association of specific factors with presence of complications among diabetic patients in Dessie Referral Hospital, 2013 ( $n=216)$.

\begin{tabular}{|c|c|c|c|c|}
\hline \multirow{2}{*}{ Variables } & \multicolumn{3}{|c|}{ Is there complication? } & \multirow{2}{*}{$P$ value } \\
\hline & Yes & No & Total & \\
\hline \multicolumn{5}{|l|}{ Age of patients } \\
\hline$<30$ & 25 & 28 & 53 & \multirow{3}{*}{0.048} \\
\hline $31-45$ & 29 & 22 & 51 & \\
\hline$>45$ & 75 & 37 & 112 & \\
\hline \multicolumn{5}{|l|}{ Sex } \\
\hline Male & 75 & 50 & 125 & \multirow{2}{*}{0.517} \\
\hline Female & 54 & 37 & 91 & \\
\hline \multicolumn{5}{|l|}{ Type of diabetes } \\
\hline Type I & 24 & 43 & 67 & \multirow{2}{*}{0.00} \\
\hline Type II & 105 & 44 & 149 & \\
\hline \multicolumn{5}{|l|}{ The regimen the patient is taking } \\
\hline Oral hypoglycemic agents & 78 & 33 & 111 & \multirow{3}{*}{0.001} \\
\hline Insulin only & 48 & 54 & 102 & \\
\hline Oral hypoglycemic agents and insulin & 2 & 1 & & \\
\hline \multicolumn{5}{|l|}{ Specific drugs } \\
\hline Glibenclamide & 17 & 1 & 18 & \multirow{5}{*}{0.00} \\
\hline Metformin & 29 & 2 & 31 & \\
\hline Glibenclamide and metformin & 39 & 23 & 62 & \\
\hline NPH insulin & 42 & 60 & 108 & \\
\hline Metformin and NPH & 2 & 1 & 3 & \\
\hline \multicolumn{5}{|l|}{ Self-reported adherence } \\
\hline Good & 36 & 30 & 66 & \multirow{2}{*}{0.303} \\
\hline Poor & 93 & 57 & 150 & \\
\hline \multicolumn{5}{|l|}{ Overall attitude scores } \\
\hline Good & 65 & 47 & 216 & \multirow{2}{*}{0.35} \\
\hline Negative/bad & 64 & 40 & 104 & \\
\hline \multicolumn{5}{|l|}{ Overall knowledge scores } \\
\hline Good & 61 & 47 & 108 & \multirow{2}{*}{0.203} \\
\hline Poor & 68 & 40 & 108 & \\
\hline
\end{tabular}

microvascular complications alone or with other macrovascular complications. It is indicated that different factors have been implicated as risks for occurrence of the complications.

In this study, $59.7 \%$ of diabetic patients had at least one diabetic complication. This was lower than the finding reported from Jimma, Ethiopia, where $83.00 \%$ of the patients had complications [7]. The majority of the complications $(48.6 \%)$ in this study were among type II patients, which is similar to another study in Jimma (52.5\%) and Taiwan $(52.6 \%)[7,38]$. The fact that a diagnosis of complications was made by general practitioners, the sociocultural differences in health seeking behavior and disclosing complications like sexual problems might result in the differences.

In this study, $70.5 \%$ of type II patients have at least one complication. This was similar to other studies in Libya (68.7\%), Iran (74.2\%), and Russia (70.7\%) [8, 21, 39]. But it was higher than another study in China (52.0\%) [22]. The difference might lie at the level of practice and the attitude and knowledge gap between the patients.

Acute complications occurred in $28.24 \%$ of the patients of which $61.71 \%$ had diabetic ketoacidosis as a complication at least once. Similar findings were reported by an earlier study in Jimma, Ethiopia [7]. Moreover, diabetic ketoacidosis occurred in both types of diabetic patients [7, 40, 41]. This indicated that diabetic ketoacidosis is the problem of both types I and II diabetes. Hyperosmolar hyperglycemic state occurred in $7.9 \%$ of patients in this study. This is high when compared with other studies in different studies which was insignificant or none $[7,8,22]$. The reason might be due to the type of medications to control the blood glucose level and poor integrated effort in the management of patients on top of poor knowledge and attitude of patients.

In this study, chronic complication occurred in more than a third of the patients (58.8\%). This is almost comparable with other reports in Jimma (52.5\%) and China (52\%) $[7,22]$ but it was lower than reports in Iran (75\%) and Libya (68.7\%) [8, 22]. Hypertension (43.3\%), visual disturbance (25.68\%), and neuropathy $(14.4 \%)$ were the commonest chronic complications in this study. Except hypertension this was similar with the study in Ethiopia (visual disturbance (33.8\%), neuropathy (29.5\%), and hypertension $(24.9 \%)$ ) but its pattern is totally different than in China $[7,22]$. The difference in management 
practitioners and the screening practices in different hospitals might have contributed to differences in occurrences of complications doubling with medication selection, poor knowledge, and attitude of patients.

In this study, age of patients, type of diabetes, antidiabetic drugs, and type of diabetes were significantly associated with the occurrences of diabetic complications in the clinic. This was similar with other studies in Ethiopia, Jordan, Libya, and Taiwan, [7, 9, 21, 38].

As limitation of study, it must be noted that this study did not determine severity of complications, and outcomes of the complications. Protein concentration, HbAlc, and direct ophthalmoscopy to detect retinal changes were not performed. Moreover, clinical findings and questionnaire based approaches were used to determine complications and the factors that could affect their occurrences.

In Conclusion. Diabetic complications in Dessie Referral Hospital were prevalent. Type II patients were more prone to complications in the hospital. The contributing factors for occurrences of complications were multiple. There should be training on the management of the diabetic patients and of course screening of complications should soon be starting. Thus, integrated effort should be in place to prevent the development of complications and manage the disease progression.

\section{Conflict of Interests}

The authors declare that they have no conflict of interests.

\section{Authors' Contribution}

Asrat Agalu Abejew was involved in the design of the study, data analysis, and interpretation of the findings, report writing, review of the report, and paper preparation. Abebe Zeleke Belay was involved in the data analysis and interpretation of the findings, and writing and review of the report. Mirkuzie Woldie Kerie was involved in the review of the final paper. All authors read and approved the final paper.

\section{Acknowledgments}

The authors are thankful to the Wollo University for funding and Dessie Referral Hospital for permission they obtained to conduct this study.

\section{References}

[1] A. S. Fauci, D. L. Kasper, D. L. Longo et al., Harrison's: Principles of Internal Medicine, McGraw-Hill, New York, NY, USA, 17th edition, 2008.

[2] M. von Korff, W. Katon, E. H. B. Lin et al., "Potentially modifiable factors associated with disability among people with diabetes," Psychosomatic Medicine, vol. 67, no. 2, pp. 233-240, 2005.

[3] E. B. Rimm, J. Chan, M. J. Stampfer, G. A. Colditz, W. C. Willett, and R. E. Laporte, "Prospective study of cigarette smoking, alcohol use, and the risk of diabetes in men," British Medical Journal, vol. 310, no. 6979, pp. 555-559, 1995.

[4] P. H. Wise, F. M. Edwardes, R. J. Craig et al., "Diabetes and associated variables in the South Australia Aboriginal," Australian \& New Zealand Journal of Medicine, vol. 6, no. 3, pp. 1991-1996, 1976.

[5] N. V. Emanuele, T. F. Swade, and M. A. Emanuele, "Consequences of alcohol use in diabetics," Alcohol Research \& Health, vol. 22, no. 3, pp. 211-219, 1998.

[6] E. Vermeire, P. van Royen, S. Coenen, J. Wens, and J. Denekens, "The adherence of type 2 diabetes patients to their therapeutic regimens: a qualitative study from the patient's perspective," Practical Diabetes International, vol. 20, no. 6, pp. 209-214, 2003.

[7] D. Worku, L. Hamza, and K. Woldemichael, "Patterns of diabetic complications at Jimma University Specialized Hospital, Southwest Ethiopia," Ethiopian Journal of Health Sciences, vol. 20, no. 1, pp. 33-39, 2010.

[8] M. H. Khazai, B. Khazai, Z. Zargaran, Z. Moosavi, and F. K. Zand, "Diabetic complications and risk factors in recently diagnosed type II diabetes: a case-control study," ARYA Journal, vol. 2, no. 2, pp. 9-83, 2006.

[9] M. Khattab, Y. S. Khader, A. Al-Khawaldeh, and K. Ajlouni, "Factors associated with poor glycemic control among patients with Type 2 diabetes," Journal of Diabetes and Its Complications, vol. 24, no. 2, pp. 84-89, 2010.

[10] J. T. Fitzgerald, R. M. Anderson, and W. K. Davis, "Gender differences in diabetes attitudes and adherence," The Diabetes Educator, vol. 21, no. 6, pp. 523-529, 1995.

[11] N. Gul, "Knowledge, attitudes and practices of type 2 diabetic patients," Journal of Ayub Medical College, Abbottabad, vol. 22, no. 3, pp. 128-131, 2010.

[12] A. H. Eldarrat, "Diabetic patients: their knowledge and perception of oral health," Libyan Journal of Medicine, vol. 6, no. 1, pp. $1-5,2011$.

[13] R. M. Anderson, M. B. Donnelly, and R. F. Dedrick, "Measuring the attitudes of patients towards diabetes and its treatment," Patient Education and Counseling, vol. 16, no. 3, pp. 231-245, 1990.

[14] M. Clark, "Adherence to treatment in patients with type 2 diabetes," Journal of Diabetes Nursing, vol. 8, no. 10, pp. 389-391, 2004.

[15] N. Hermanns, M. Mahr, B. Kulzer, S. E. Skovlund, and T. Haak, "Barriers towards insulin therapy in type 2 diabetic patients: results of an observational longitudinal study," Health and Quality of Life Outcomes, vol. 8, article 113, 2010.

[16] M. Peyrot, R. R. Rubin, T. Lauritzen, F. J. Snoek, D. R. Matthews, and S. E. Skovlund, "Psychosocial problems and barriers to improved diabetes management: results of the Cross-National Diabetes Attitudes, Wishes and Needs (DAWN) Study," Diabetic Medicine, vol. 22, no. 10, pp. 1379-1385, 2005.

[17] E. H. B. Lin, M. von Korff, P. Ciechanowski et al., "Treatment adjustment and medication adherence for complex patients with diabetes, heart disease, and depression: a randomized controlled trial," Annals of Family Medicine, vol. 10, no. 1, pp. 6-14, 2012.

[18] E. A. Ajayi and A. O. Ajayi, "Pattern and outcome of diabetic admissions at a federal medical center: a 5-year review," Annals of African Medicine, vol. 8, no. 4, pp. 271-275, 2009.

[19] A. Chijioke, A. N. Adamu, and A. M. Makusidi, "Mortality patterns among type 2 diabetes mellitus patients in Ilorin, Nigeria," Journal of Endocrinology, Metabolism and Diabetes of South Africa, vol. 15, no. 2, pp. 79-82, 2010. 
[20] D. Bradshaw, V. Pillay-Van Wyk, R. Laubscher et al., Cause of Death Statistics for South Africa: Challenges and Possibilities for Improvement, South Africa Burden of Disease Research Unit, 2010.

[21] R. B. Roaeid and A. A. Kablan, "Diabetes mortality and causes of death in Benghazi: a 5-year retrospective analysis of death certificates," Eastern Mediterranean Health Journal, vol. 16, no. 1, pp. 65-69, 2010.

[22] Z. Liu, C. Fu, W. Wang, and B. Xu, "Prevalence of chronic complications of type 2 diabetes mellitus in outpatients-a cross-sectional hospital based survey in urban China," Health and Quality of Life Outcomes, vol. 8, article no. 62, 2010.

[23] J. Peter, C. K. Riley, B. Layne, K. Miller, and L. Walker, "Prevalence and risk factors associated with erectile dysfunction in diabetic men attending clinics in Kingston, Jamaica," Journal of Diabetology, vol. 2, article 2, 2012.

[24] A. Raval, E. Dhanaraj, A. Bhansali, S. Grover, and P. Tiwari, "Prevalence \& determinants of depression in type 2 diabetes patients in a tertiary care centre," Indian Journal of Medical Research, vol. 132, no. 8, pp. 195-200, 2010.

[25] P. Mukhopadhyay, B. Paul, D. Das, N. Sengupta, and R. Majumder, "Perceptions and practices of type 2 diabetics: a cross-sectional study in a tertiary care hospital in Kolkata," International Journal of Diabetes in Developing Countries, vol. 30, no. 3, pp. 143-149, 2010.

[26] R. I. Ekore, I. O. Ajayi, A. Arije, and J. O. Ekore, "Attitude, diabetic foot care, education, knowledge: type 2 diabetes mellitus," African Journal of Primary Health Care \& Family Medicine, vol. 2, p. 10, 2010.

[27] J. N. Kalyango, E. Owino, and A. P. Nambuya, "Non-adherence to diabetes treatment at mulago hospital in Uganda: prevalence and associated factors," African Health Sciences, vol. 8, no. 2, pp. 67-73, 2008.

[28] A. R. Khan, Z. N. Al-Abdul Lateef, M. A. Al Aithan, M. A. BuKhamseen, I. Al Ibrahim, and S. A. Khan, "Factors contributing to non-compliance among diabetics attending primary health centers in the Al Hasa district of Saudi Arabia," Journal of Family and Community Medicine, vol. 19, no. 1, pp. 26-32, 2012.

[29] Institute for Clinical Systems Improvement, Health Care Guideline: Diagnosis and Management of Type 2 Diabetes Mellitus in Adults, 2012, https://www.icsi.org/.

[30] R. Sharma, V. L. Grover, and S. Chaturvedi, "Recipe for diabetes disaster: a study of dietary behaviors among adolescent students in south Delhi, India," International Journal of Diabetes in Developing Countries, vol. 31, no. 1, pp. 4-8, 2011.

[31] R. Yadav, P. Tiwari, and E. Dhanaraj, "Risk factors and complications of type 2 diabetes in Asians," CRIPS, vol. 9, no. 2, pp. $8-12,2008$.

[32] J. J. Holewski, K. M. Moss, R. M. Stess, P. M. Graf, and C. Grunfeld, "Prevalence of foot pathology and lower extremity complications in a diabetic outpatient clinic," Journal of Rehabilitation Research and Development, vol. 26, no. 3, pp. 35-44, 1989.

[33] C. L. Triplitt, C. A. Reasner, and W. L. Isley, Pharmacotherapy: A Pathophysiologic Approach, edited by J. T. Dipiro, R. L. Talbert, G. C. Yee, McGraw-Hill, New York, NY, USA, 7th edition, 2008.

[34] P. H. Rayappa, K. N. M. Raju, A. Kapur, S. Bjork, C. Sylvest, and K. M. D. Kumar, "Economic cost of diabetes care the bangalore urban district diabetes study," International Journal of Diabetes in Developing Countries, vol. 19, pp. 87-97, 1999.
[35] P. Urbansk, A. Wolf, and W. Herman, Cost-effectiveness Issues of Diabetes Prevention and Treatment, https://dpg-storage.s3 .amazonaws.com/dce/resources/cost_effective.pdf.

[36] D. F. Williamson, F. Vinicor, and B. A. Bowman, "Primary prevention of type 2 diabetes mellitus by lifestyle intervention: implications for health policy," Annals of Internal Medicine, vol. 140, no. 11, pp. 951-957, 2004.

[37] S. E. Skovlund and M. Peyrot, "The diabetes attitudes, wishes, and needs (DAWN) program: a new approach to improving outcomes of diabetes care," Diabetes Spectrum, vol. 18, no. 3, pp. 136-142, 2005.

[38] G. D. Chen, C. N. Huang, Y. S. Yang, and C. Y. Lew-Ting, "Patient perception of understanding health education and instructions has moderating effect on glycemic control," BMC Public Health, vol. 14, no. 1, article 683, 2014.

[39] L. Litwak, S.-Y. Goh, Z. Hussein, R. Malek, V. Prusty, and M. E. Khamseh, "Prevalence of diabetes complications in people with type 2 diabetes mellitus and its association with baseline characteristics in the multinational Alchieve study," Diabetology and Metabolic Syndrome, vol. 5, no. 1, article 57, 2013.

[40] American Diabetes Association, "Standards of medical care in diabetes-2013," Diabetes Care, vol. 36, supplement 1, pp. S11S66, 2013.

[41] A. E. Kitabchi, G. E. Umpierrez, J. M. Miles, and J. N. Fisher, "Hyperglycemic crises in adult patients with diabetes," Diabetes Care, vol. 32, no. 7, pp. 1335-1343, 2009. 


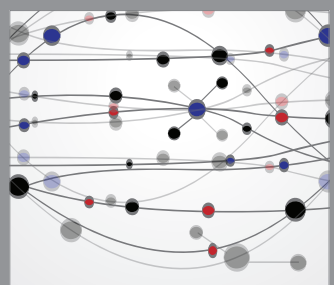

The Scientific World Journal
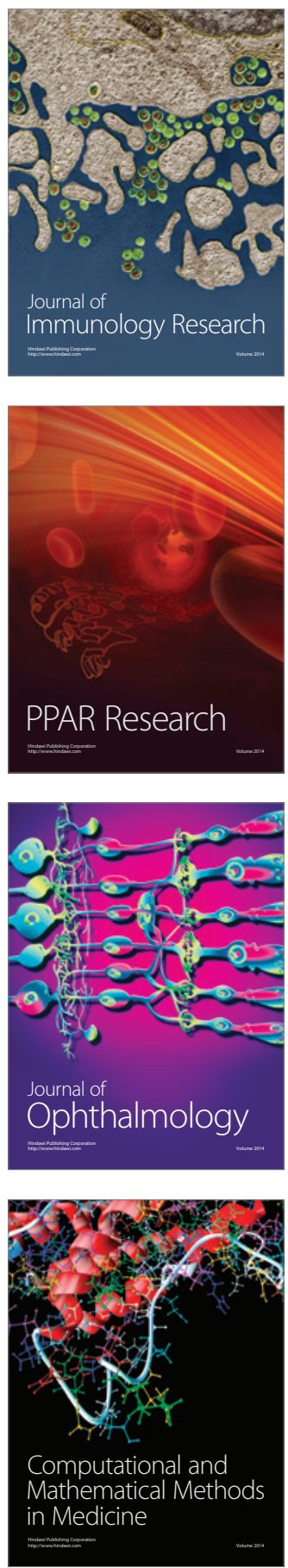

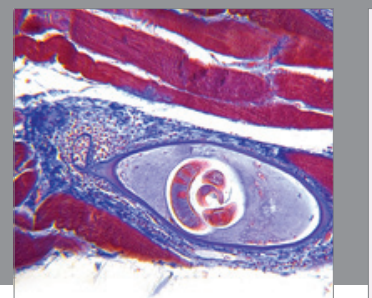

Gastroenterology

Research and Practice
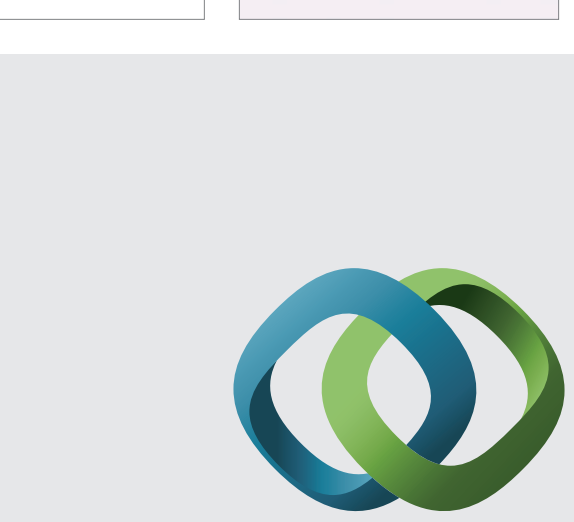

\section{Hindawi}

Submit your manuscripts at

http://www.hindawi.com
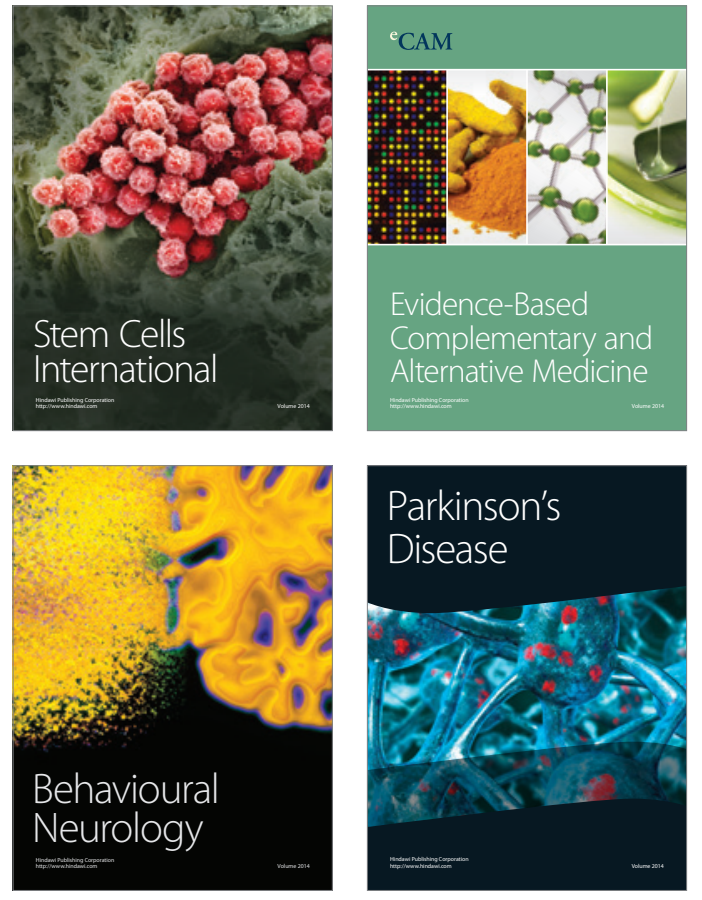
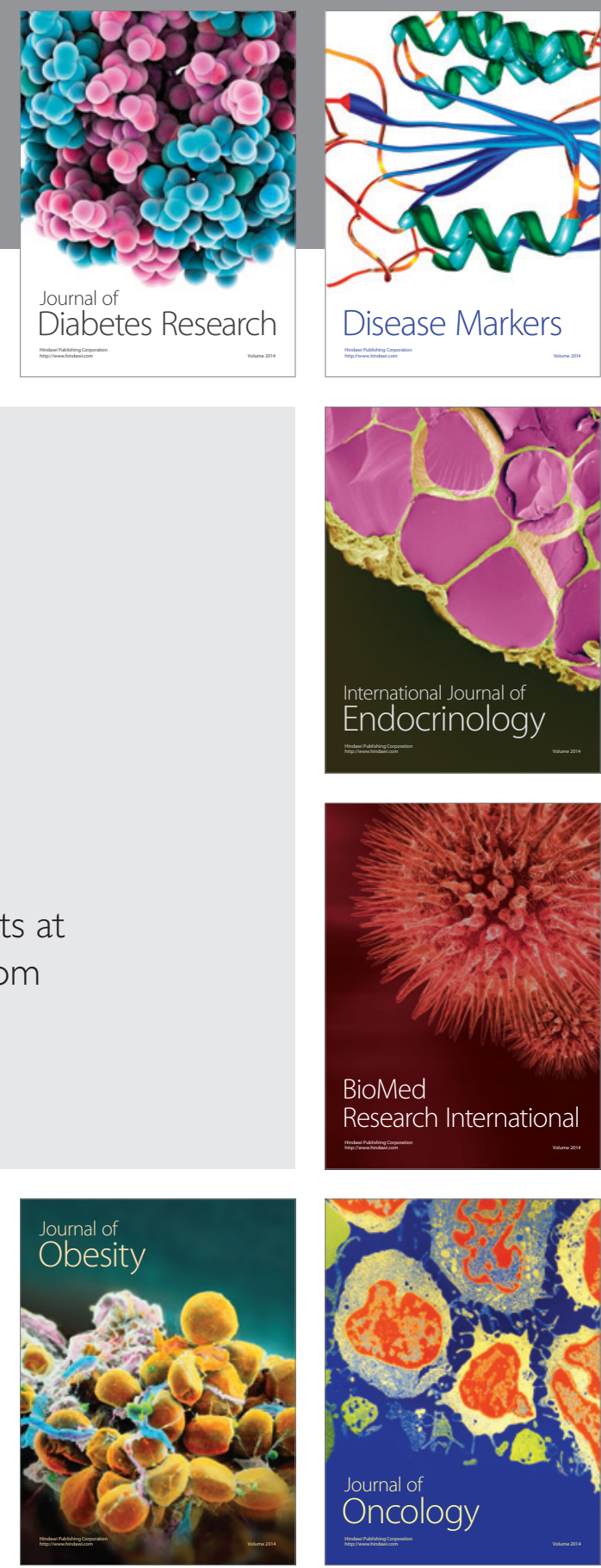

Disease Markers
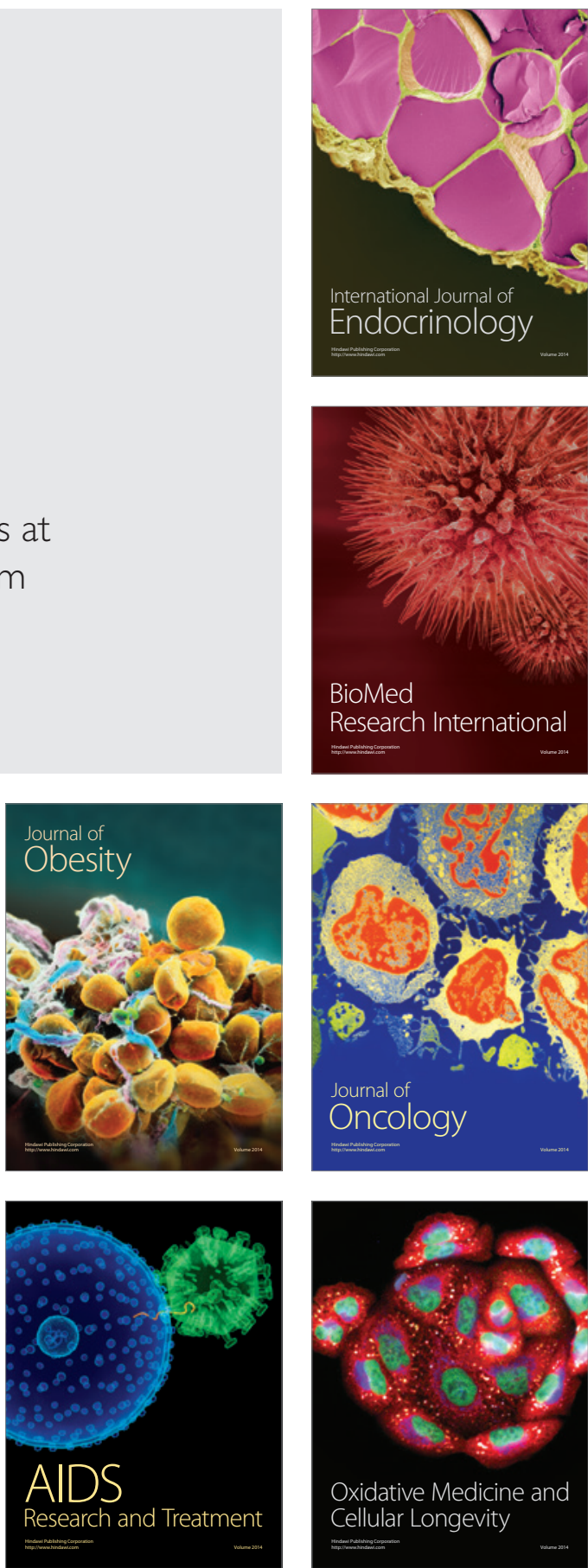